\title{
GM1 gangliosidosis type 1
}

INSERM

\section{Source}

INSERM. (1999). Orphanet: an online rare disease and orphan drug data base. GM1 gangliosidosis type 1. ORPHA:79255

GM1 gangliosidosis type 1 is the severe infantile form of GM1 gangliosidosis (see this term) with variable neurological and systemic manifestations. 